Article

\title{
Mechanical and Durability Properties of Cement-Stabilized Recycled Concrete Aggregate
}

\author{
Qingfu Li and Jing $\mathrm{Hu}$ * \\ School of Water Conservancy Engineering, Zhengzhou University, Zhengzhou 450003, China; lqflch@zzu.edu.cn \\ * Correspondence: jing_hu@gs.zzu.edu.cn
}

Received: 1 August 2020; Accepted: 7 September 2020; Published: 9 September 2020

\begin{abstract}
This research investigates the effect of using recycled concrete aggregate (RCA) as a partial replacement of natural aggregate (NA) on the mechanical and durability-related properties of a cement-stabilized recycled concrete aggregate (CSR) mixture. In this case, mixtures were prepared with $0 \%, 40 \%, 70 \%$, and $100 \%$ (by weight) RCA to replace NA, and cement contents of $4 \%, 5 \%$, and $6 \%$ were used in this study. Test parameters included the replacement ratio, cement content, and curing time. Tests were carried out to establish the unconfined compressive strength (UCS), indirect tensile strength (ITS), drying shrinkage, and water loss ratio of each mix proportion. The preliminary results of UCS and ITS tests indicated that the incorporation of RCA resulted in a decrease of strength compared with a cement-stabilized macadam (CSM) mixture, but the seven-day strength of the CSR mixture met the related requirements of road bases. The increase in cement content and curing time had an obvious effect on strength improvement. The drying shrinkage test showed that the drying shrinkage properties of the CSR mixture were obviously reduced with a high replacement ratio. It is evident that the CSM mixture presented a better drying shrinkage performance than that of the CSR mixture.
\end{abstract}

Keywords: recycled concrete aggregate; cement-stabilized macadam; replacement ratio; cement content; curing time

\section{Introduction}

Semi-rigid bases are widely used in highway bases and sub-base systems due to their higher strength, greater rigidity, better uniformity, and water stability [1]. Among them, cement-stabilized macadam (CSM) is the most common in pavement bases, comprising aggregates of graded crushed stone and a certain amount of cement slurry and mortar as aggregate fillers [2]. In many countries, using CSM as the base course is very popular because it enhances the load-carrying capacity of asphalt pavement structures [3]. Moreover, CSM can decrease the tensile strain of the bottom of bituminous layers because of its better bearing capacity [4]. With the rapid development of road construction, a large amount of natural high-quality aggregates, such as basalt, used for CSM is increasingly consumed. It is expected that, in the next two to three decades, the demand for natural aggregates (NAs) will double [5]. For some economically underdeveloped and remote areas, road construction is a great challenge because of the shortage of aggregate resources; nevertheless, long-distance aggregate transportation demands a larger workforce and more financial capital, which is neither economical nor environmentally friendly. Therefore, finding an NA substitute to reduce the stone resource shortage is an important research direction.

In recent years, on the basis of the development concept of industrialization and urbanization, many old bridges, roads, and buildings were demolished, producing much construction and demolition waste (CDW). It is estimated that, in terms of construction and building activities, about $40 \%$ of energy and $50 \%$ of natural resources are depleted, causing $15 \%-30 \%$ of total solid-waste production [6], 
of which waste concrete is one of the main components. According to the investigation of Lu et al. [7], the overall amount of building-related CDW was approximately 1.13 billion tons in China in 2014, excluding the amount for the renovation of existing buildings. The most common treatment for this CDW is to dump it into landfills, which puts considerable pressure on landfill capacity and seriously pollutes land and water [8]. Simultaneously, it was established that this waste material contributes to global warming. So far, waste concrete in CDW that is randomly piled up has not been fully utilized, and the overall amount of waste concrete continues to rise. Natural aggregate, which cannot be produced in the short term, generally accounts for $60 \%$ to $75 \%$ of concrete by volume [9]; therefore, the concrete industry consumes a lot of natural aggregates. Road construction has a high demand of aggregates, thus it would be profitable to use waste concrete to manufacture recycled aggregate and apply it in a CSM mixture, which can be an effective way to significantly alleviate the shortage of natural aggregate resources while contributing to minimizing environmental burdens caused by the disposal of waste concrete and energy consumption.

Recycled concrete aggregates (RCAs) are aggregate particles attached to old cement mortar and produced by crushing demolished waste concrete. It was demonstrated that RCAs contribute to sustainability and present practical applications based on the economic considerations of the construction industry [10], which is consistent with the concept of "sustainable buildings" proposed by Dr. Charles Cabot. Similarly, Kirthika et al. [11] reported that the utilization of alternative fine aggregates (crushed rock sand, industrial by-products, and recycled fine aggregates) with concrete helps to promote economic, sustainability, and social benefits. In conclusion, the production of recycled aggregates using waste concrete is potentially a sustainable way to reduce environmental and economic impact and increase social benefits. Considering the huge consumption of NAs and the high production of waste concrete, RCAs are suitable for application to the construction industry.

Regeneration of construction waste such as waste concrete used in road bases has been researched for several decades, developing advanced recycling technology and relevant RCA specifications. Since the 1840s, developed regions such as Europe and the United States have taken the lead in researching the application of construction waste to pavement bases, roadbeds, and shoulders, but only little waste is used for pavements [12]. In the United States, more than 20 states have adopted RCAs in highway construction, of which 15 formulated RCA regulations [13]. For example, RCAs were used by the Michigan Department of Transportation in the early 1980s to rebuild several interstate highways. In fact, the characteristics of RCAs make them suitable for the production of recycled aggregate concrete (RAC) [14]. In the past two decades, RCAs have been extensively used in the manufacture of concrete, namely recycled aggregate concrete (RAC). According to previous studies, RACs have excellent environmental [15] and excellent economic [16] benefits. Kampala et al. [17] reported that the reuse of recycled materials has significant carbon savings in comparison with extracting original quarried materials. Moreover, the application of recycled aggregates decreases the consumption of natural stone, which, in turn, reduces economic costs and the environmental burden. A literature review indicated that the research on variables that affect RCA pavement performance mainly focused on discussing the influence of either replacement ratio [18-21] or particle size $[22,23]$. By analyzing their experiment results, it was found that the compressive strength of RACs is lower than that of parent concrete. Compared with the parent concrete, the compressive strength of RACs is decreased by $25 \%$ [21]. On the other hand, compressive strength is not the only factor that decides the mechanical properties and durability of RACs: under the same compressive strength level, the performance of different RAC mixtures is subjected to the particle size and content of the coarse aggregate [24]. In addition, cement-stabilized CDW, such as recycled asphalt pavement [25,26], steel slag [27], and crushed brick [27], was investigated to be viable construction material for pavement base or sub-base utilization, but the factors that affect the properties of cement-stabilized recycled material have not been comprehensively and systematically studied. Further analysis showed that the strength and durability of CSR mixtures are greatly susceptible to cement content, and their traffic capacity can be flexibly changed by an increase or decrease in cement content to achieve the desired 
purpose [28]. However, previous studies related to RCAs focused on a comprehensive investigation of mechanical properties with fewer variables or lesser levels of variables, and few further analyzed multiple factors and levels with regard to the performance of RCA mixtures [18-23].

At present, the investigation and application of recycled cement concrete aggregate from pavement slab in road base are in the preliminary stage of research, discussion, and experimentation in China. According to [29], the use of cement-treated RCA has not been extensively evaluated. There still exist many problems, like the lack of an RCA crushing process, the poor strength of RCA mixture, and differences in waste material. The existing research verified the good effect of RCA on pavement bases or sub-bases, and there is a preliminary discussion about their mechanism. However, the evaluation of RCA applied to a CSM mixture on multiple factors and levels is rare, and the study of the mechanism is insufficient. In addition, previous studies only discussed the effect of a single variable on the mechanical properties of CSR mixtures. In this paper, the strength ratio is introduced, and the contribution of each factor to the strength increment is discussed through the control variable method to carry out a composition design of a CSR mixture from a more reasonable and economical perspective. With the acceleration of infrastructure construction, recycling waste concrete becomes more urgent and necessary. In this study, RCA was employed to replace NA as the main material for road base construction. The purpose of this paper is to systematically evaluate the performance of CSR mixtures incorporated with a different replacement ratio and cement content under various curing times from the aspect of strength and shrinkage; results are compared with those of a CSM mixture. Furthermore, this paper could be helpful in providing a theoretical foundation and reference for the design and performance assessment of CSR mixtures.

\section{Materials and Methods}

\subsection{Materials}

\subsubsection{Cement}

Ordinary Portland cement was used in this study, and its physical and mechanical properties provided by the manufacturer are shown in Table 1.

Table 1. Physical and mechanical properties of Portland cement.

\begin{tabular}{cccccccc}
\hline \multirow{2}{*}{ Type } & & \multicolumn{5}{c}{ Physical Performance } \\
\cline { 3 - 7 } & Comparison & Setting Time (h) & \multicolumn{3}{c}{ Strength (MPa) } \\
\cline { 3 - 7 } & & & & Flexural Strength & \multicolumn{2}{c}{$\begin{array}{c}\text { Unconfined } \\
\text { Compressive Strength }\end{array}$} \\
\cline { 3 - 7 } & & Initial Set & Final Set & $\mathbf{3 d}$ & $\mathbf{2 8 d}$ & $\mathbf{3 d}$ & $\mathbf{2 8 d}$ \\
\hline \multirow{2}{*}{ P.O 42.5 } & Reference value & $\geq 0.75$ & $\leq 6$ & $\geq 3.5$ & $\geq 6.5$ & $\geq 17$ & $\geq 42.5$ \\
& Test result & 3 & 3.8 & 5.6 & 9.3 & 30.9 & 53.7 \\
\hline
\end{tabular}

\subsubsection{Aggregates}

The NAs (crushed limestone) were sourced locally in central China, and RCAs were sourced from a waste concrete pavement slab in Xuchang, Henan. In the production of RCAs: (1) impurities like branches were removed from the waste concrete; (2) the demolished concrete was crushed by a jaw crusher and an impact crusher to obtain concrete blocks; and (3) the concrete blocks were sieved to form aggregates with different grades. After the above procedures, RCAs were graded by particle size into four levels (i.e., $0-5 \mathrm{~mm}, 5-10 \mathrm{~mm}, 10-20 \mathrm{~mm}$, and 20-30 mm), of which the aggregates with $0-5 \mathrm{~mm}$ particle size were used as recycled fine aggregates, and those greater than $5 \mathrm{~mm}$ but less than $30 \mathrm{~mm}$ were used as recycled coarse aggregates. The NAs used in this study were sieved and graded in accordance with the RCAs to maintain consistency. 
Tables 2 and 3 present the main physical characteristics of the coarse aggregate and fine aggregates, respectively, and the test methods were in accordance with JTG E42-2005 [30]. As can be seen in Table 2, the crushing and abrasion values of the recycled coarse aggregate were much higher than those of the natural coarse aggregate, indicating that the recycled aggregate had poor mechanical strength.

Table 2. Physical characteristics of coarse aggregate.

\begin{tabular}{ccc}
\hline Test Indicators & Natural Coarse Aggregate & Recycled Coarse Aggregate \\
\hline Apparent density $\left(\mathrm{g} / \mathrm{cm}^{3}\right)$ & 2.729 & 2.662 \\
Crushing value $(\%)$ & 13.7 & 20.8 \\
Los Angeles abrasion value $(\%)$ & 19.7 & 26.4 \\
Water absorption $(\%)$ & 0.7 & 2.81 \\
Needle and flake content $(\%)$ & 6.4 & 8.9 \\
Mud content $(\%)$ & 0.8 & 1.4 \\
\hline
\end{tabular}

Table 3. Physical characteristics of fine aggregate.

\begin{tabular}{ccc}
\hline Test Indicators & Natural Fine Aggregate & Recycled Fine Aggregate \\
\hline Apparent density $\left(\mathrm{g} / \mathrm{cm}^{3}\right)$ & 2.639 & 2.512 \\
Water absorption $(\%)$ & 2.6 & 9.2 \\
Mud content $(\%)$ & 1.6 & 4.2 \\
Fineness modulus & 3.64 & 3.12 \\
Water content $(\%)$ & 2.4 & 3 \\
\hline
\end{tabular}

It can also be seen from Table 2 that the water absorption of recycled coarse aggregate is approximately 4 times that of natural coarse aggregate, thus the amount of water should be properly increased when preparing an RCA mixture to ensure good quality. Seen from Table 3, the mud content of recycled fine aggregate far outweighed that of natural fine aggregate, exceeding the requirement of [30] of no more than $2 \%$, leading to an increase in drying shrinkage. It can be concluded from Tables 2 and 3 that RCA showed higher water absorption and lower density compared with NA. These observations are because of micro-cracks and pores on the surface of RCA, resulting in high water absorption, low density, and strength [4].

\subsection{Experimental Program}

\subsubsection{Gradation Design}

At first, the natural limestone was used in the CSM as the control group, and the natural coarse (5-30 $\mathrm{mm})$ and fine $(0-5 \mathrm{~mm})$ aggregates were then replaced by RCAs in the same particle size range in proportions of $40 \%, 70 \%$, and 100\%, named CSR (40), CSR (70), and CSR (100), respectively. On the condition of fully considering impacts such as residual porosity, four mixtures were sieved to determine the optimal mixing proportion of aggregates with different particle sizes for the purpose of continuous grading.

According to the gradation composition of NAs and RCAs, the gradation of aggregates is presented in Figure 1.

In China, for CSM mixtures, the cement content is usually less than 6\% [8]; thus, in this paper, cement contents of $4 \%, 5 \%$, and $6 \%$ were chosen for the mixtures to analyze the effects of the cement content. Based on a compaction test, the maximum dry density and the optimum water content of each mix proportion are presented in Table 4 . It can be seen from Table 4 that, under the same cement content, with the increase of replacement ratio, the maximum dry density of CSR mixtures slowly decreased, while the optimum water content showed an obvious increase in connection with the high water absorption of RCA. Taking the $5 \%$ cement content as an example, the maximum dry density of the CSM mixture was approximately 1.1 times that of CSR (100) mixture, while the optimum water 
content was about 0.5 times. Cement content had no significant effects on the maximum dry density of the CSR mixture and CSM mixtures, but the optimum water content of CSR mixtures steadily increased with the increase of cement content. The specimens were prepared at the optimum water content and maximum dry density to guarantee strength and stability.

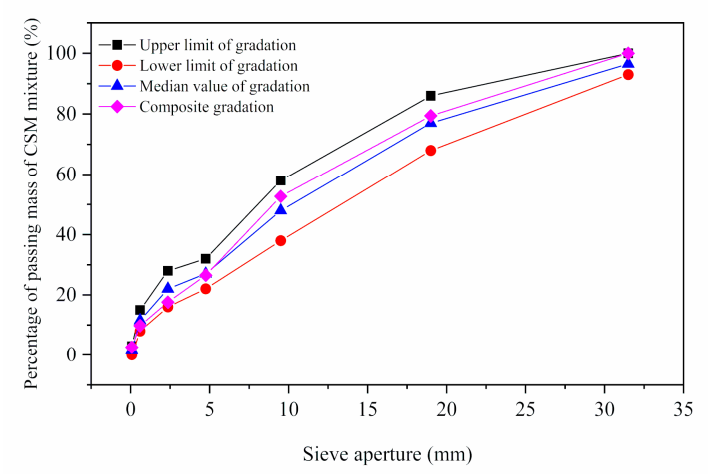

(a)

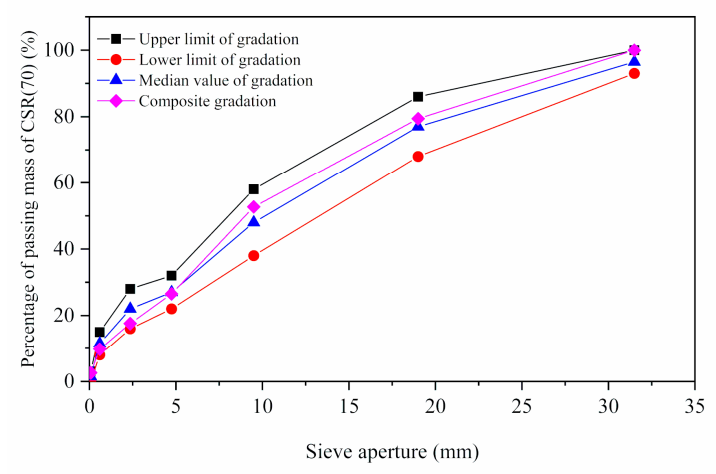

(c)

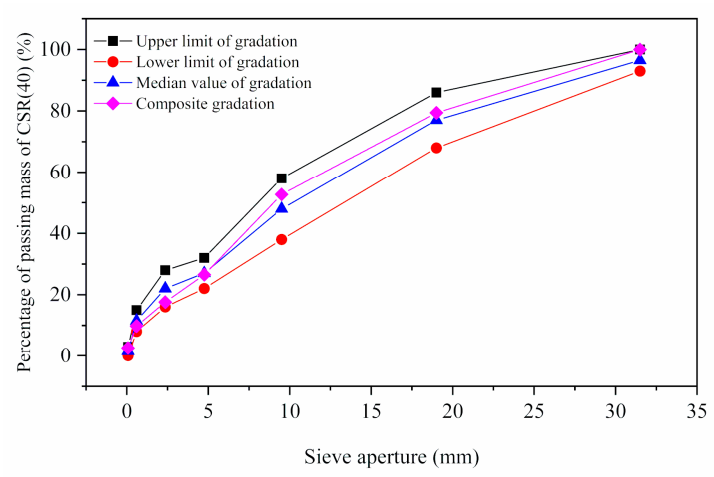

(b)

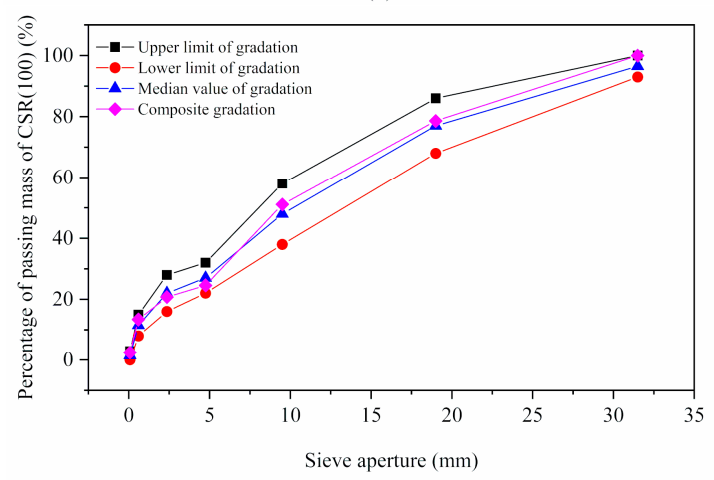

(d)

Figure 1. Gradation curve of different mixtures: (a) cement-stabilized macadam (CSM) mixture; (b) cement-stabilized recycled concrete aggregate (CSR) (40) mixture; (c) CSR (70) mixture; (d) CSR (100) mixture.

Table 4. Maximum dry density and optimum water content of the mixtures.

\begin{tabular}{|c|c|c|c|}
\hline Cement Content (\%) & Replacement Ratio (\%) & Maximum Dry Density $\left(\mathrm{g} / \mathrm{cm}^{3}\right)$ & Optimum Water Content (\%) \\
\hline \multirow{4}{*}{4} & 0 & 2.256 & 4.1 \\
\hline & 40 & 2.224 & 6.4 \\
\hline & 70 & 2.022 & 8.1 \\
\hline & 100 & 2.007 & 8.5 \\
\hline \multirow{4}{*}{5} & 0 & 2.286 & 4.4 \\
\hline & 40 & 2.239 & 7.3 \\
\hline & 70 & 2.030 & 8.9 \\
\hline & 100 & 2.015 & 9.4 \\
\hline \multirow{4}{*}{6} & 0 & 2.303 & 4.5 \\
\hline & 40 & 2.250 & 8.1 \\
\hline & 70 & 2.049 & 9.4 \\
\hline & 100 & 2.026 & 10.1 \\
\hline
\end{tabular}

\subsubsection{Unconfined Compressive Strength and Indirect Tensile Strength Tests}

The unconfined compressive strength and indirect tensile strength tests were conducted in accordance with JTG E51-2009 [31]. Standard test specimens of $\Phi 150 \times 150 \mathrm{~mm}$ used for the tests were formed by a compressor with a loading rate of $1 \mathrm{~mm} / \mathrm{min}$ on the CSM or CSR mixture, corresponding to a compaction degree of $98 \%$. Then, specimens were cured for $7,28,60$, and 90 days under standard curing conditions with a temperature of $20 \pm 2{ }^{\circ} \mathrm{C}$ and relative humidity over $95 \%$. Afterward, 
specimens were placed on a universal test machine with a flat ball seat on the lift platform, and the loading rate was manually set at $1 \mathrm{~mm} / \mathrm{min}$. The test results were the average of six repetitive specimens from each given specification.

\subsubsection{Drying Shrinkage Test}

The drying shrinkage test was carried out on specimens with $5 \%$ content cement. CSM and CSR mixtures were cast into $100 \times 100 \times 400 \mathrm{~mm}$ beam specimens and cured for 7 days under standard conditions. Then, specimens were taken out and placed onto a glass plate, which was air-dried under natural temperature and humidity. Finally, the water loss ratio and drying shrinkage of the specimens at different times were measured until the water content of the specimen was no longer reduced, and the volume of the specimen was basically unchanged. Six repetitive specimens were prepared for each group, and test results were averaged.

\section{Test Results}

The following display a series of tests results on the UCS, ITS, drying shrinkage strain, and water loss ratio of various mix proportions.

\subsection{Unconfined Compressive Strength}

Unconfined compressive strength (UCS) is generally considered as a key indicator for assessing the properties of CSM mixtures. In this study, UCS was affected by three mixed variables, which are cement content, replacement ratio of RCA, and curing time.

\subsubsection{Effect of the Replacement Ratio of Recycled Concrete Aggregate}

It is widely known that the UCS of CSM is closely related to the strength of aggregates in the mixture. The influence of the replacement ratio of RCA on UCS is displayed in Figure 2, where C means cement content, similarly hereinafter.

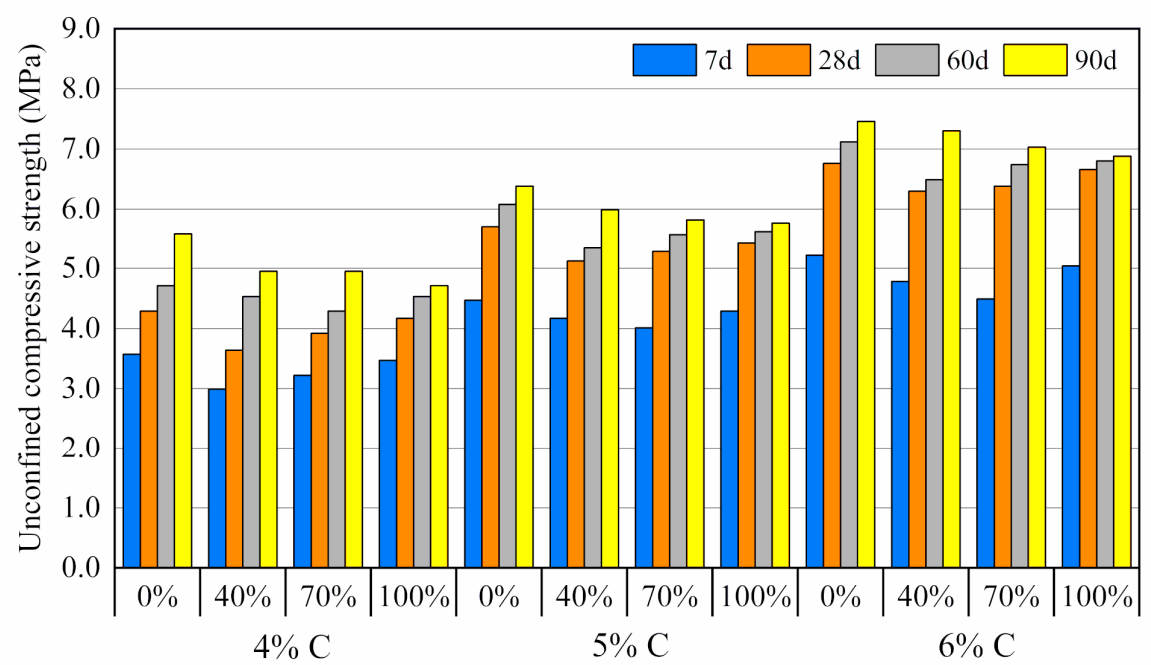

Figure 2. Relationship between unconfined compressive strength and replacement ratio. C: cement content.

Figure 2 shows that the UCS value of the CSR mixtures was always worse than that of the CSM mixture. Taking the cement content of $5 \%$ and 28 days curing time as an example, the UCS of CSR (100) was approximately $95 \%$ of that of the UCS of the CSM mixture. Similarly, Rahal [32] reported that the 28-day cube and cylinder compressive strength of RAC were, on average, $90 \%$ of those of natural aggregate concrete with the same mix of proportions. As can be seen in the same figure, the overall trend of the UCS of different mixtures varied with the increase of replacement ratio under different 
curing times. With the increasing of replacement ratio, UCS initially decreased, followed by a slight increase during a curing period of fewer than 60 days, and UCS constantly decreased during a curing period of 90 days; these phenomena were more obvious in the CSR mixtures with a relatively high cement content (e.g., $5 \%$ and $6 \%$ ).

These observations were because RCA is a type of granular material; UCS is not only bound up with the strength of the aggregate itself but related to the interfacial bonding strength of aggregate-aggregate and aggregate-cement mortar. Commonly, the greater the strength of aggregate is, the greater the compressive strength of the CSR mixture is. As a matter of fact, the negative effect of replacement ratio on strength is essentially subject to the mortar content. RCA contains cement mortar and aggregates attached to the mortar, and both form large mortar clumps that can be easily separated by an external force; thus, the strength of RCA is decreased, and the UCS of the CSR mixture is reduced. The positive influence of replacement ratio on strength enhancement is mainly divided into three parts: (1) un-hydrated mortar reacted with RCA to form hydraulic products; (2) RCA had a rough surface with many edges, thereby increasing frictional resistance between aggregates; (3) there are a lot of micro-cracks on the surface of RCA; hence, it was easier for cement mortar to infiltrate the RCA interior to fill the void, leading to an improvement in interfacial strength. All of the above increase the strength of CSR mixtures [33]. When negative impact exceeds positive influence, strength decreases, and vice versa.

In general, UCS development with the replacement ratio of RCA has a strong relationship with cement content and curing time; consequently, there are different laws on UCS development.

\subsubsection{Effect of Cement Content}

Cement content takes an important role in UCS attributing to its substantial improvement in the strength and quality of CSM and CSR mixtures. In order to analyze the influence of cement content on the UCS of the CSR mixture and CSM mixtures, a total of four groups of mixtures were tested with cement contents of $4 \%, 5 \%$, and $6 \%$. The representative values of UCS and the ratio to that with the cement content of $4 \%$ are displayed in Figure 3.

Figure 3a shows that the UCS of the CSR and CSM mixtures tended to linearly increase with the increase of cement content. For instance, as cement content increased from $4 \%$ to $5 \%$ during a curing time of 60 days, the strength of CSR (70) rose to about $1.27 \mathrm{MPa}$, while cement content from $5 \%$ to $6 \%$ led to a rise of $1.18 \mathrm{MPa}$; the difference between these two strength increments was only 0.09 $\mathrm{MPa}$. It was established in a previous study that the development rate of the UCS of a traditional CSM mixture is nearly proportional to cement content [34]. Therefore, combined with the above results, cement content has an excellent effect on the strength because cement enhanced the material's strength, and the bonding force between particles was improved by the increase in hydration products.

As Figure $3 \mathrm{~b}$ shows, when curing time was less than 28 days, the strength of the CSR (40) mixture increased slightly more with the increase of cement content compared with the mixtures in the three other groups. For instance, under 28 days' age, the strength of CSR (40) mixture increased by approximately $73 \%$ as cement content increased from $4 \%$ to $6 \%$, while the one of the CSM mixture only increased by $58 \%$. Generally speaking, the strength improvements of CSR mixtures were relatively close, showing that the contribution of cement to strength has no significant relationship with the replacement ratio of RCA but is related to the variation of curing time, and 28 days of age corresponds to the maximum increase in UCS.

Therefore, a proper increase of cement content could, to some degree, make up for the low strength of RCA. According to JTG D50-2017 [35], the UCS of cement-stabilized bases used in heavy and medium/light traffic roads in curing periods of seven days should range from 4.0 MPa to 6.0 MPa and 3.0 MPa to 5.0 MPa, respectively. Experiment results indicated that when cement content is $5 \%$ or $6 \%$, the UCS of CSR mixtures satisfies the requirements for the use of bases in heavy traffic conditions, and when cement content is $4 \%$, the UCS of CSR mixtures is between $2.99 \mathrm{MPa}$ and 3.57 MPa, which almost meets the requirements of medium /light traffic roads. Obviously, the strength 
of CSR mixtures can be reduced to meet the requirements of light traffic conditions by decreasing the cement content.

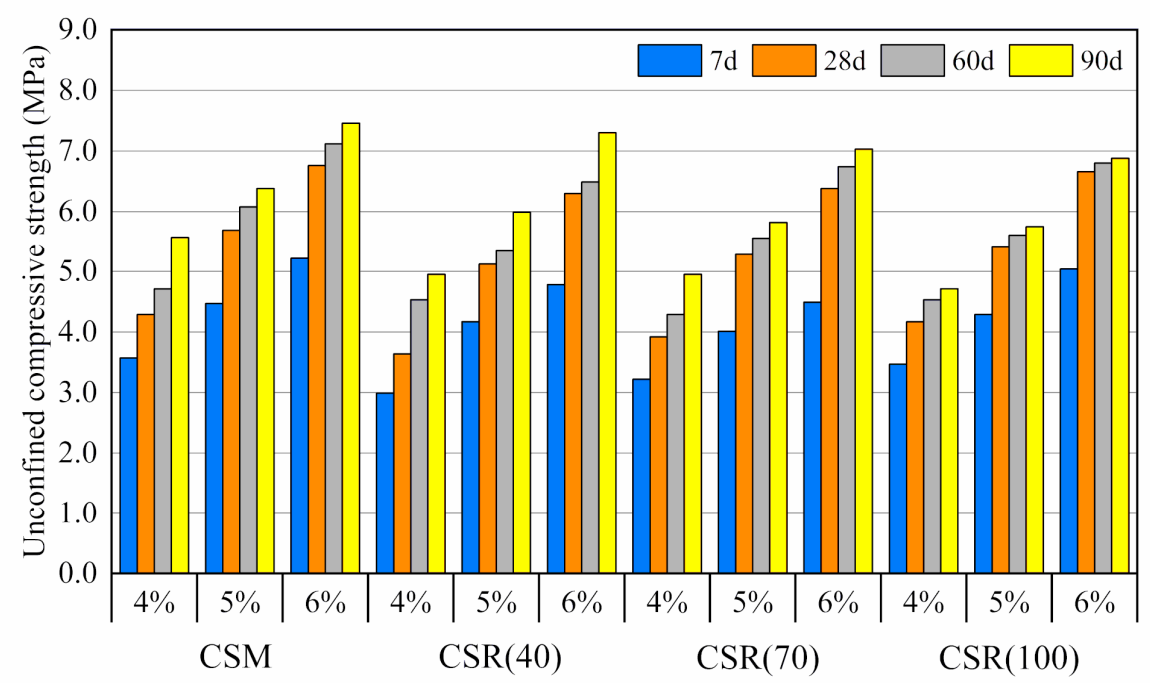

(a)

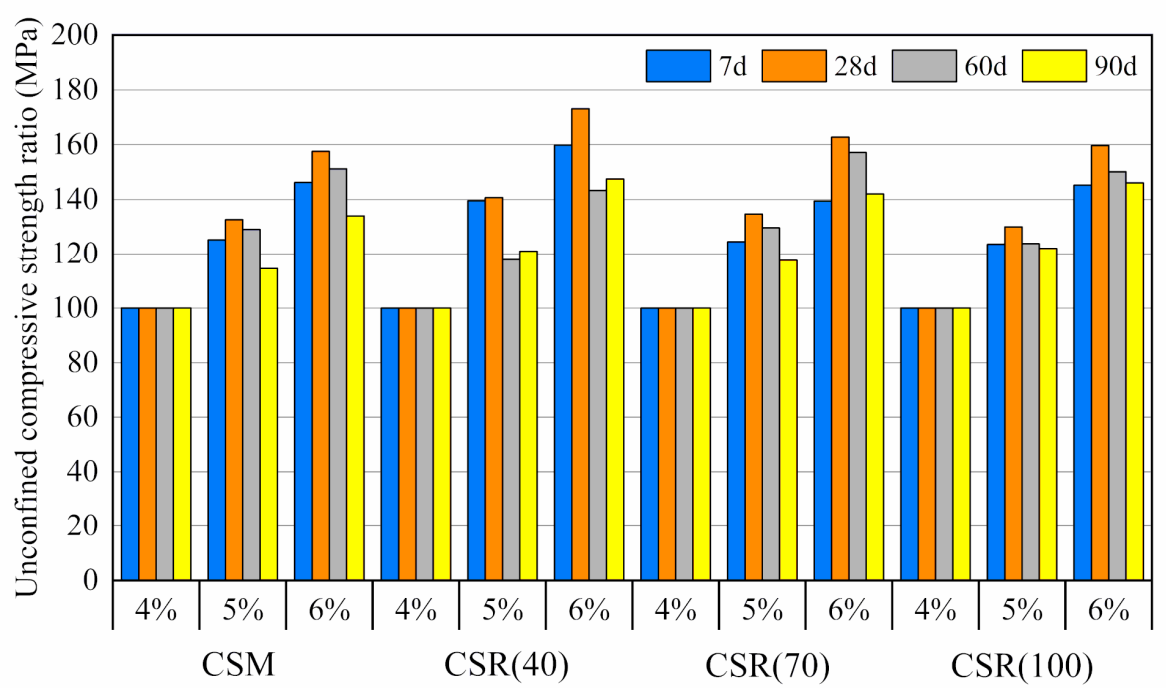

(b)

Figure 3. Relationship between unconfined compressive strength and cement content: (a) Unconfined compressive strength with cement content; (b) Unconfined compressive strength ratio with cement content.

\subsubsection{Effect of Curing Time}

In order to analyze the effect of curing time on the UCS of CSR mixtures, the four sets of mixtures were tested with curing times of $7,28,60$, and 90 days. The experimental data of UCS and the ratio to that with the curing time of seven days are displayed in Figure 4.

As shown in Figure 4a, with the increase of curing periods, the strength of both CSM mixture and CSR mixture increases. This is because the hydrated reaction is dependent on time. With more cement added to the mixture, lots of hydration products are produced which have vigorous influences on the strength improvement and bonding effect. Moreover, curing time seems to have less effect on the strength growth with its increase. Seen from Figure 4a, the strength develops rapidly in the first 28 days, however it increases slowing down since the curing time over 60 days. Taking the $6 \%$ 
cement content as an example, when the curing period increases from 7 days to 28 days, the strength of CSR (100) increases by approximately $32 \%$, while the strength just increases by $2 \%$ from 28 days to 60 days; additionally, the strength with the age of 90 days is only $1 \%$ higher than that of 60 days. Meanwhile, Liu et al. [36] carried out a series of UCS tests on cement-stabilized aggregate containing bottom ash aggregate, and the growth curve is similar to the experiment results in this study with curing periods increasing. The above phenomenon is due to un-hydrated cement granules being surrounded with formed cement slurry, thus it is difficult for water to contact cement particles without hydration, and therefore the hydration reaction of cement is hindered in the late stage, resulting in a slower growth of UCS.

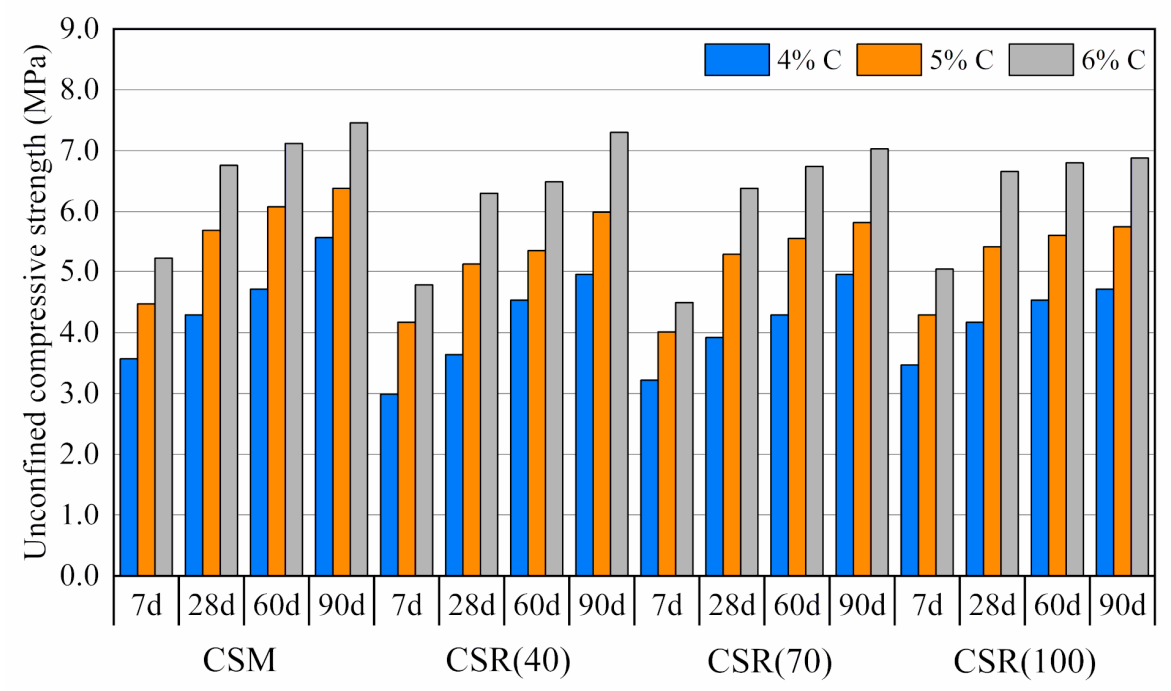

(a)

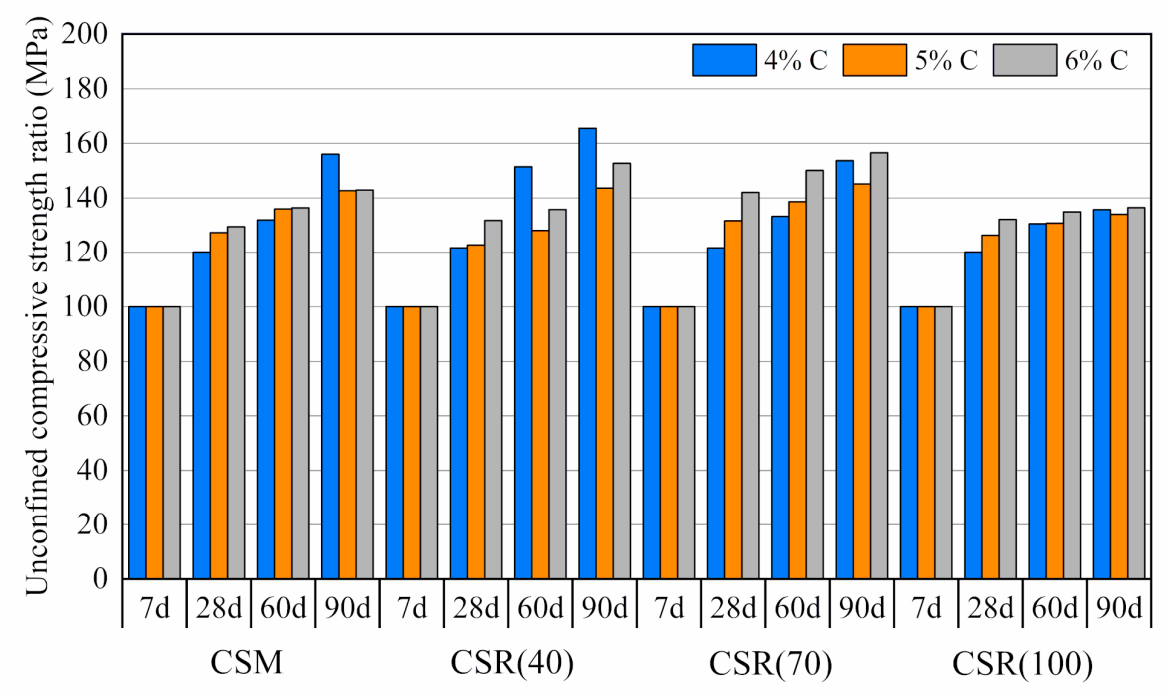

(b)

Figure 4. Relationship between unconfined compressive strength and curing time: (a) Unconfined compressive strength with curing time; (b) Unconfined compressive strength ratio with curing time.

Figure $4 \mathrm{~b}$ shows that the effect of curing time on the strength growth of CSM, CSR (40), and CSR (70) was slightly greater in comparison to that on CSR (100). For instance, the maximum strength increment of CSR (100) was just 37\%, while one of the CSR (40) was $66 \%$ when curing time increased 
from 7 to 90 days. That is because CSR (100) contained more active materials on the RCA surface, which could cause a pozzolanic reaction with $\mathrm{Ca}(\mathrm{OH})_{2}$ in hydration products, leading to the faster growth of UCS [37]. However, the improvement of the strength caused by the pozzolanic reaction still cannot balance the reduction in strength resulting from the low strength of RCA. As a result, the strength growth rate of the mixture with a higher replacement ratio was worse than that with a lower replacement ratio, when curing time was the same. Moreover, on the basis of strength improvement, it is more economical to use $4 \%$ cement content for CSM and CSR mixtures with a long curing time.

\subsection{Indirect Tensile Strength}

\subsubsection{Effect of the Replacement Ratio of Recycled Concrete Aggregate}

Experiment data of the indirect tensile strength (ITS) of CSM and CSR mixtures with various replacement ratios are presented in Figure 5. It is obvious from Figure 5 that the strength of the CSM mixture was higher than that of the three groups of CSR mixtures with the same cement content, which was similar to UCS. Moreover, the development of ITS was initially decreased, subsequently increased with a replacement ratio increase, and the minimum strength value appeared at a replacement ratio of $40 \%$. However, as the replacement ratio increased, the difference of ITS between CSM and CSR mixtures was reduced. For example, the strength of CSR (40) was about 0.87 times that of CSM, while the strength of CSR (100) was about 98\%. This phenomenon might be because the elastic modulus between the hardened mortar binder and recycled aggregate greatly differs, and their deformation is inconsistent when subjected to external loading, thus generating additional tension [38]. The development of ITS with replacement ratio was similar to that of compressive strength in a period of fewer than 60 days.

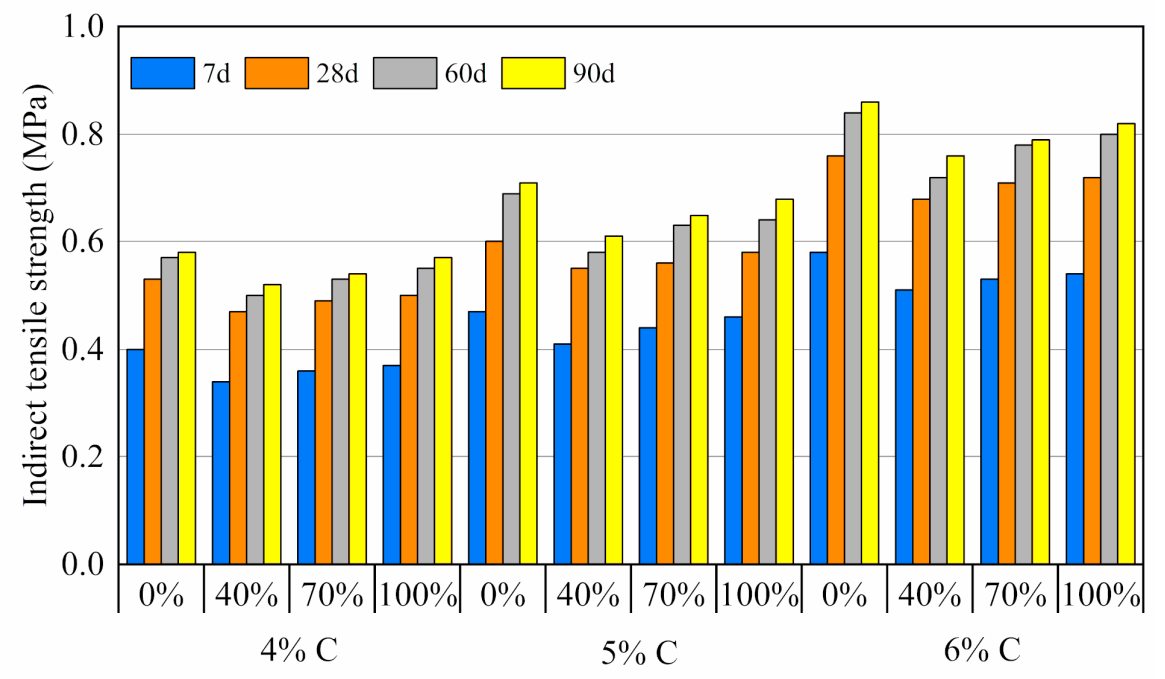

Figure 5. Relationship between indirect tensile strength and replacement ratio.

\subsubsection{Effect of Cement Content}

In order to analyze the effect of cement content on the ITS of the CSR and CSM mixtures, specimens were tested with cement contents of $4 \%, 5 \%$, and $6 \%$. The experiment data of ITS and the ratio to that with a cement content of $4 \%$ are displayed in Figure 6. As Figure 6a shows, a positive correlation is found between the ITS of CSM as well as the CSR mixture and cement content. With the same cement content, the sequence of ITS from large to small is CSM, CSR (100), CSR (70), and CSR (40). As seen from Figure $6 \mathrm{~b}$, it is apparent that cement content had no significance on the strength growth of CSR mixtures with various replacement ratios and curing time, demonstrating that the effect of cement content on the development of ITS barely related to the replacement ratio and age. In fact, the mechanism of cement content on ITS is similar to that on UCS. RCA contains high mortar and 
water contents, with the increase of cement content, it provides a mass of cement particles which can react with the water in RCA to produce amounts of hydration products, and cement can stimulate the residual activity of mortar, resulting in the ITS of CSR mixtures being more sensitive to cement content [1]. Therefore, the two aspects contribute to the rapid improvement of mixture strength. However, the strength enhancement resulting from mortar and water contents cannot remedy the decrease in strength resulting from the low strength of RCA. This is because the strength of CSR mixtures is lower than that of CSM mixtures with the same cement content.

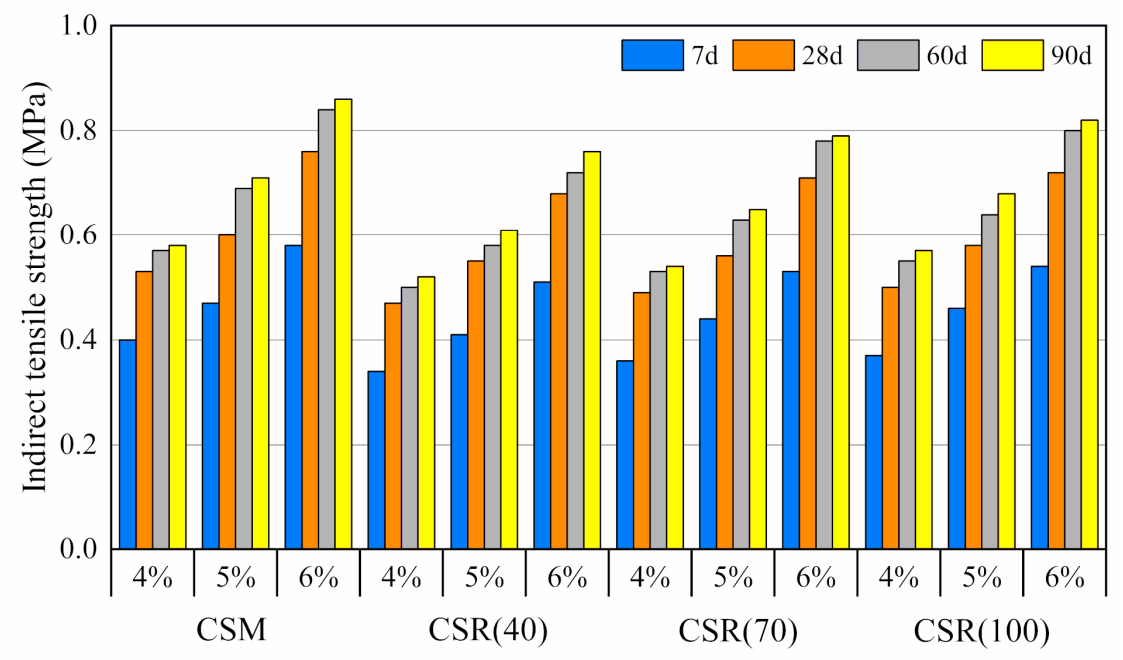

(a)

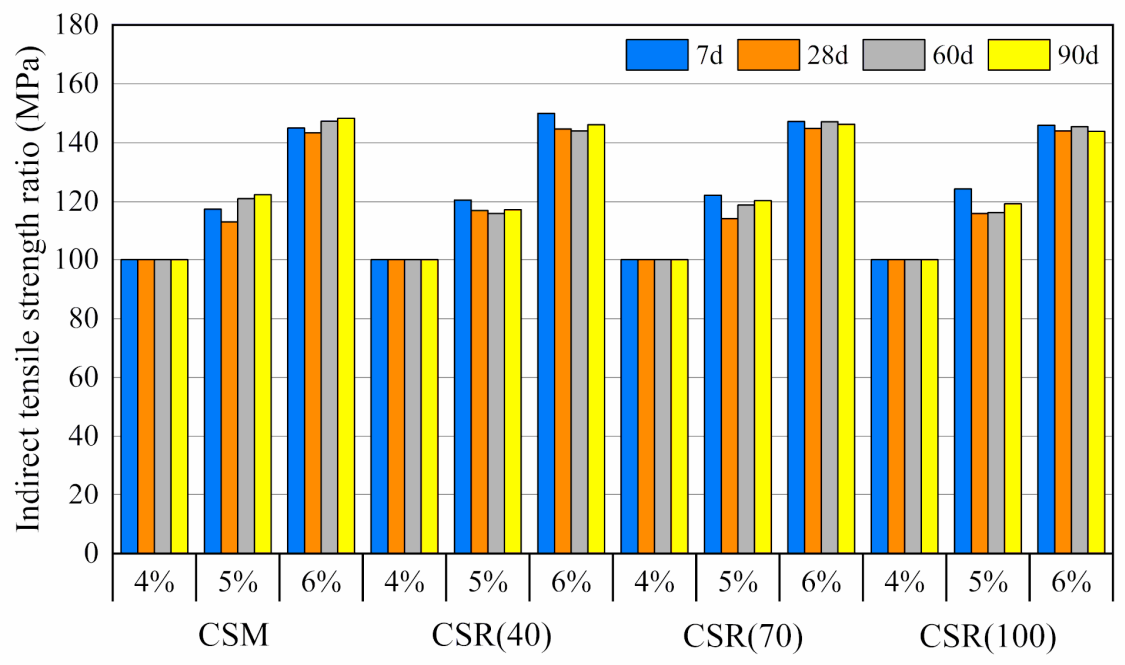

(b)

Figure 6. Relationship between indirect tensile strength and cement content: (a) Indirect tensile strength with cement content; (b) Indirect tensile strength ratio with cement content.

\subsubsection{Effect of Curing Time}

For the purpose of analyzing the influence of curing time on the ITS of CSM and CSR mixtures, different mixture proportions were tested with the ages of $7,28,60$, and 90 days. The experiment values of ITS and the ratio to that with the curing time of seven days are presented in Figure 7. As can be seen from Figure 7a, with the increase of the curing period, the ITS of both CSR and CSM mixtures increased. Strength increased rapidly from 7 to 28 days but decreased slowly later than that period. Taking the $5 \%$ cement content as an example, when curing time increased from 7 to 28 days, the strength of the CSR (40) mixture increased by approximately $34 \%$, while the strength increased 
by only $5.2 \%$ from 60 to 90 days. In the same curing period, the sequence of the strength was CSM, CSR (100), CSR (70), and CSR (40). Figure 7b shows that curing time had an equal influence on the ITS and UCS of the mixtures, except for CSR (100), where the curing period had more influence on ITS than UCS from Figure $4 \mathrm{~b}$. For instance, the UCS of CSR (100) increased by about $37 \%$, and the ITS of CSR (100) increased by approximately $51 \%$ when the curing period increased from 7 to 90 days and cement content was $6 \%$. This is because of the strength of the mixture coming from the embedding force and frictional resistance between aggregates, and the interfacial bonding between aggregate and cement mortar. Regarding external force, UCS depends on frictional resistance and embedding force, while ITS depends on the interfacial bonding between aggregate and mortar [28], which has a strong relationship with curing time. With the increase of the curing period, the strength of the CSR mixture is significantly improved via the interfacial bonding enhanced. In a word, ITS growth with the curing period is better than that of UCS under a high replacement ratio. In addition, under the same replacement ratio and age, it is sustainable for CSR mixtures to use low cement content under the condition of high strength increments.

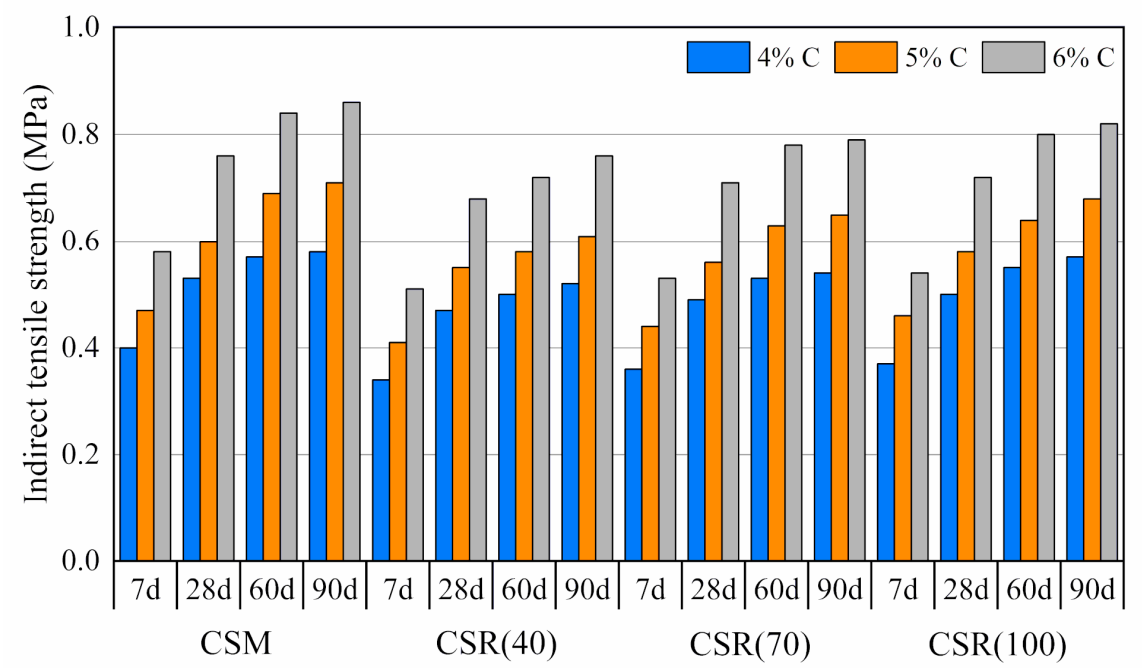

(a)

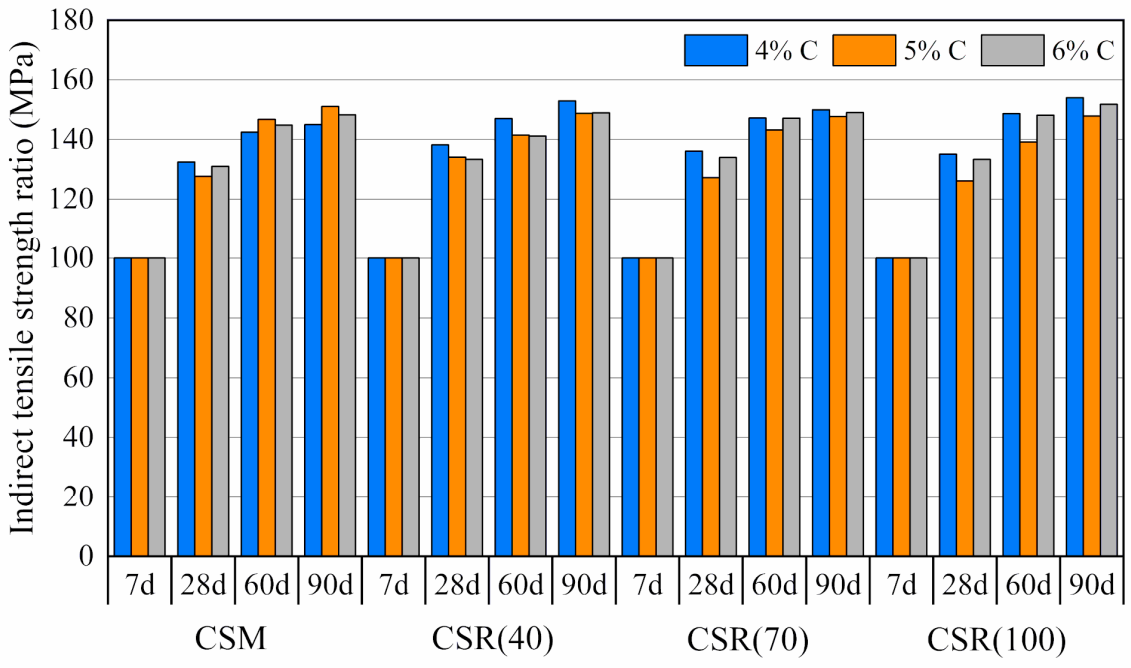

(b)

Figure 7. Relationship between indirect tensile strength and curing time: (a) Indirect tensile strength with curing time; (b) Indirect tensile strength ratio with curing time. 


\subsection{Relationship between UCS and ITS}

Figure 8 shows the fitting curve of UCS and ITS values of CSM and CSR mixtures at the different replacement ratios of RCA. From the curve, it can be seen that the UCS value is about 10 times the ITS value, which is applicable to all cement-stabilized aggregates in this study. This result demonstrated that there is a certain correlation between ITS and UCS no matter the mixture composition (replacement ratio of RCA, cement content, and curing period). Generally, the tensile strength of concrete ranged from $1 / 20$ to $1 / 10$ of compressive strength. For natural aggregate mixtures with disparate amounts of cement content, there is a linear relationship between UCS and ITS, that is, UCS $=9.8 \times$ ITS [25], which is consistent with the experiment results in this study. Therefore, the results of this paper are reasonable.

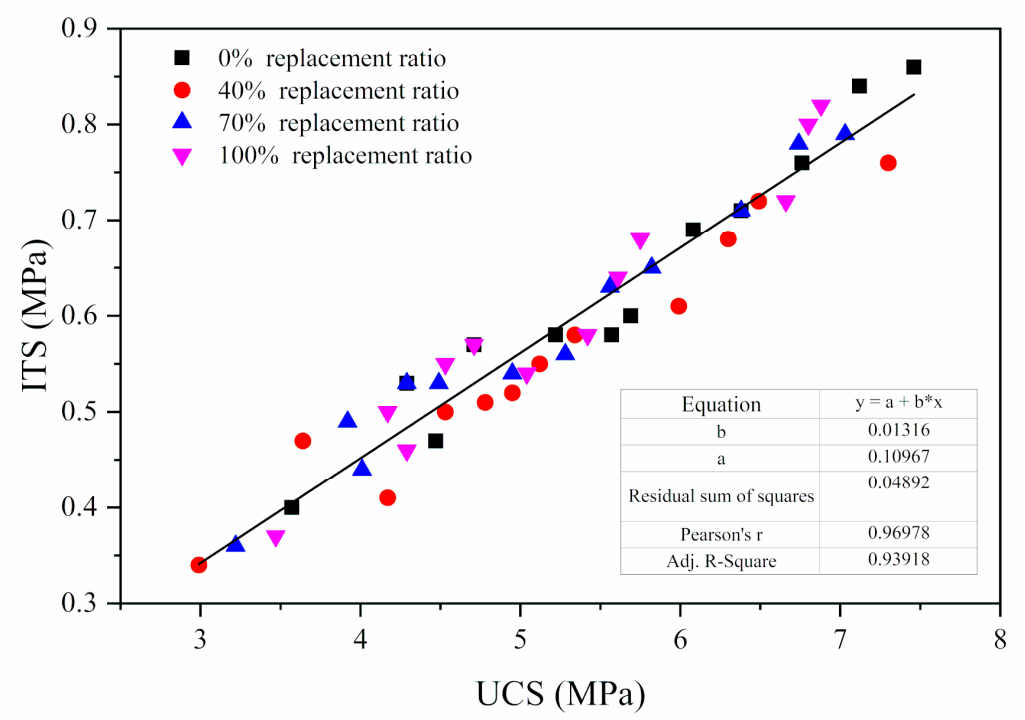

Figure 8. Relationship between unconfined compressive strength (UCS) and indirect tensile strength (ITS).

\subsection{Durability-Related Properties}

\subsubsection{Drying Shrinkage}

In order to analyze the influence of drying shrinkage of CSM and CSR mixtures, the four groups of mixtures were tested with replacement ratios of $0 \%, 40 \%, 70 \%$, and $100 \%$, and cement content was $5 \%$. The development of the total amount of drying shrinkage with the replacement ratio of RCA is shown in Figure 9, which shows the total amount of drying shrinkage increasing with replacement ratio increasing. For replacement ratios of less than $40 \%$, the drying shrinkage growth rate was slight, and shrinkage was more sensitive to the replacement ratio when it exceeded $40 \%$, which was more obvious with replacement ratios from $40 \%$ to $70 \%$.

The growth of drying shrinkage strain with time in Figure 10 shows that, as test age increased, drying shrinkage strain nearly linearly increased in the early period and slowed down in the late period. In addition, all CSR mixtures almost achieved final drying shrinkage at 31 days. Gao et al. [39] reported that the development of drying shrinkage probably ended in about 30 days, which agrees with this study. Moreover, at a given test age, CSR mixtures containing much more RCA showed higher shrinkage strain in all mixtures. For example, the drying shrinkage strain of CSR (40) was about 1.33 times that of CSM at five days, which indicated that the drying shrinkage characteristics of RCA have few differences with those of NA. However, with regard to the drying shrinkage strain of CSR (40), that of CSR (70) increases by almost 2.11 times; thus, if the replacement ratio was as high as $70 \%$ or more, it would be appropriate to extend the curing time to alleviate the linear increase in drying shrinkage in actual applications. In addition, the CSM mixture presented lower drying shrinkage 
strain and the total amount of drying shrinkage in comparison to those of CSR mixtures. According to Katz [40], this is due to the high porosity of RCA, thus its ability to inhibit the deformation of cement slurry is worse than that of NA.

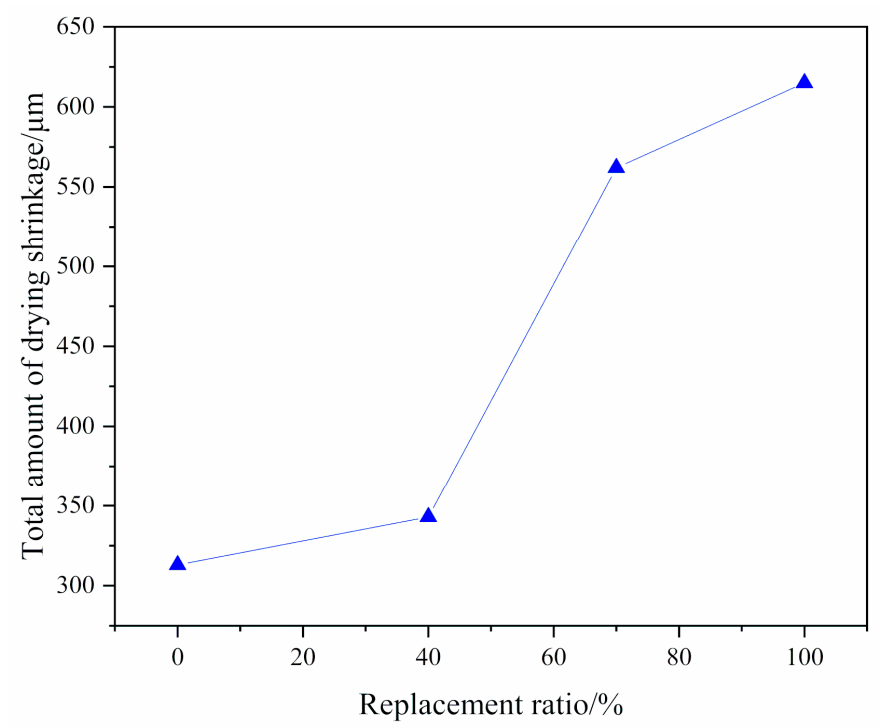

Figure 9. Total amount of drying shrinkage with different replacement ratios.

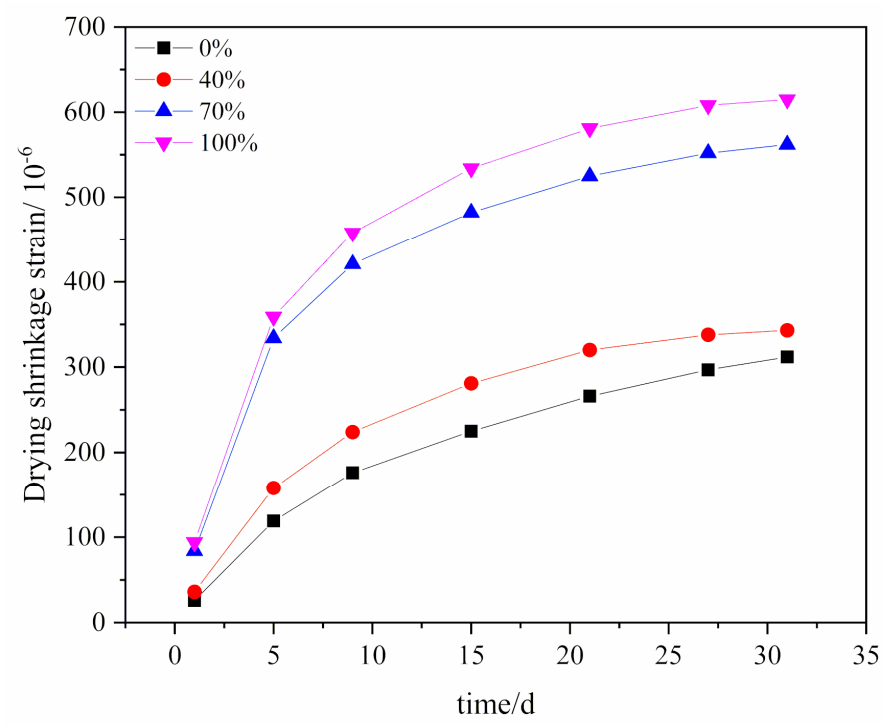

Figure 10. Development of drying shrinkage with time.

\subsubsection{Water Loss Ratio}

The development of the water loss ratio with the replacement ratio of RCA and time is displayed in Figures 11 and 12. With the increase of replacement ratio, the water loss cycle of CSR mixtures was constantly shrinking, while the water loss ratio was continuously increasing. For instance, CSR (100) reached the state of full water loss in 25 days, while CSR (40) did so in 31 days; furthermore, the water loss ratio of the former was higher than that of the latter. This shows that, although the increase of RCA increased the optimal water content of the mixture, it was easier to lose water under dry conditions. As can be seen from Figure 12, the total amount of the water loss ratio of the CSM was 3.29\%, and that of CSR (40) differed little from that, showing that their water retention was relatively close. With the replacement ratio increasing from $40 \%$ to $70 \%$ and $100 \%$, the water loss ratio of CSR mixtures was about 1.57 and 1.64 times that of CSM, respectively. This means that, as the replacement ratio was 
less than $40 \%$, the water loss ratio of the drying shrinkage was dominated by the NA, but when the replacement ratio exceeded $70 \%$, the water loss ratio was dominated by the RCA.

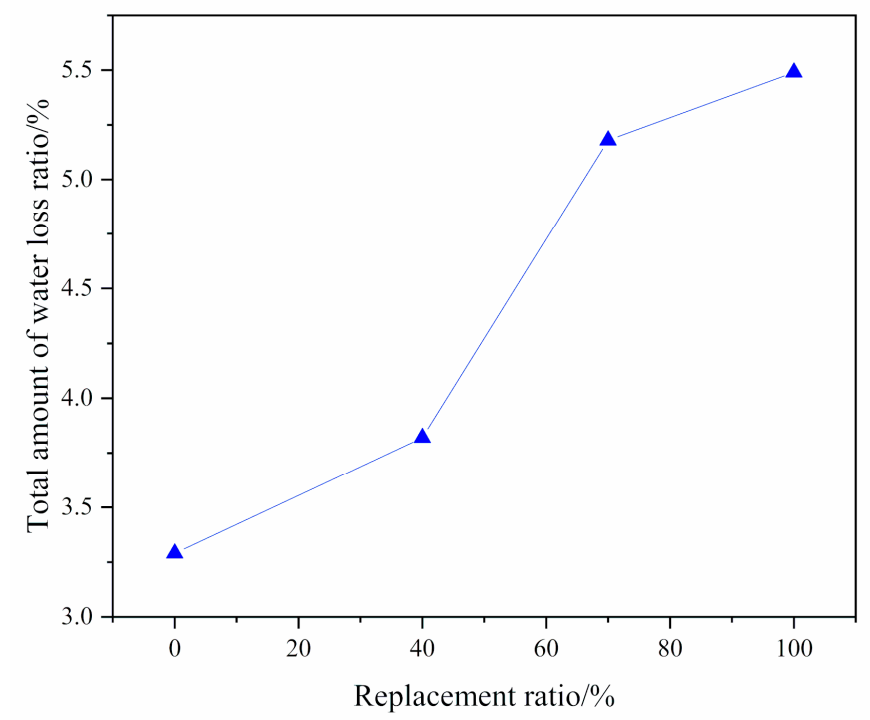

Figure 11. Total amount of the water loss ratio with different replacement ratios.

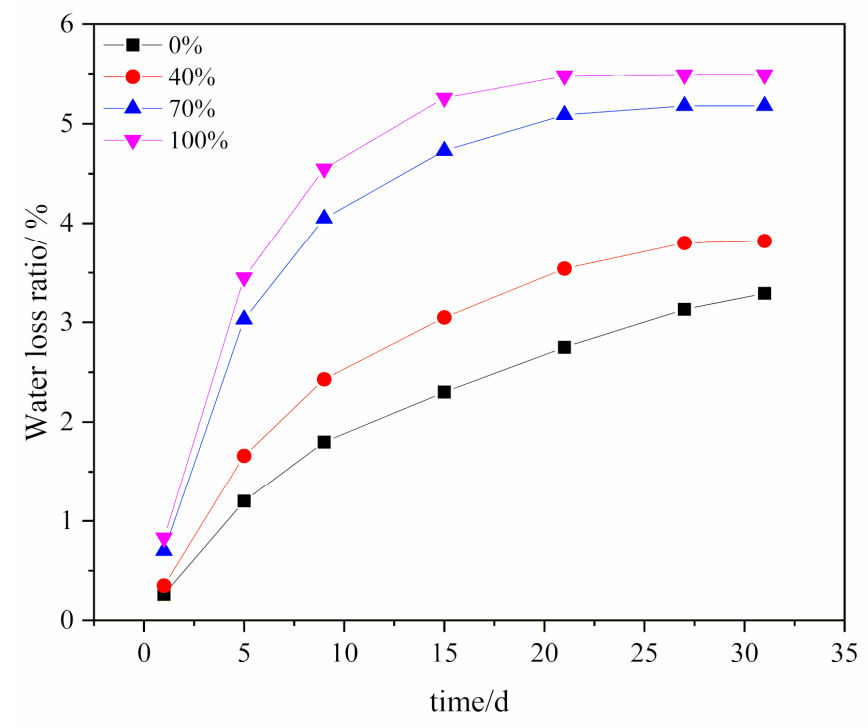

Figure 12. Development of the water loss ratio with time.

\section{Conclusions}

In this paper, RCA was designed to replace the NA of CSM with different proportions. Then laboratory tests were conducted to investigate the performance of strength- and durability-related properties of a CSR mixture, and they were compared with a traditional CSM mixture. The following conclusions could be drawn:

1. When the curing time was fewer than 60 days, a lower replacement ratio resulted in an initial decrease in the UCS of the CSR mixture; with the increase of the replacement ratio, the UCS had a slight increase. When curing time exceeded 60 days, the UCS of the CSR mixture decreased with the replacement ratio. The seven-day UCS of the CSR mixture met the requirements for road base applications. The ITS of the CSR mixture decreased and then increased with the replacement ratio. The UCS and ITS of the CSM mixture were higher than those of the CSR mixture. 
2. The UCS and ITS of the CSR mixture with a higher cement content were better, and UCS was significantly increased after 28 days of curing. Compared to the CSM mixture, the CSR mixture had lower strength with the same cement content.

3. For four different curing times, the development rate of the UCS and ITS of the CSR mixture from 7 to 28 days was the maximum, which then gradually decreased with curing time. Longer curing caused a further hydration reaction, thus leading to high strength levels. It is economical to use low cement content in the same age for CSR mixtures.

4. The drying shrinkage strain of the CSR mixture increased with the increase of the replacement ratio but decreased with time. A high replacement ratio corresponded to high drying shrinkage strain.

5. The development of the water loss ratio indicated that it was easier for the CSR mixture to lose water under dry conditions. The drying shrinkage strain and water loss ratio of the CSR mixture more obviously increased in the RCA range of $40 \%-70 \%$. The higher the replacement ratio was, the shorter the water loss cycle.

Author Contributions: All authors contributed equally to this work. All authors wrote, reviewed, and commented on the manuscript. All authors have read and agreed to the published version of the manuscript.

Funding: This research received no external funding.

Conflicts of Interest: The authors declare no conflict of interest.

\section{References}

1. Sun, Y.; Li, L. Strength assessment and mechanism analysis of cement stabilized reclaimed lime-fly ash macadam. Constr. Build. Mater. 2018, 166, 118-129. [CrossRef]

2. Lv, S.T.; Yuan, J.; Liu, C.C.; Wang, J.Q.; Li, J.L.; Zheng, J.L. Investigation of the fatigue modulus decay in cement stabilized base material by considering the difference between compressive and tensile modulus. Constr. Build. Mater. 2019, 223, 491-502. [CrossRef]

3. Du, S.W. Influence of chemical additives on mixing procedures and performance properties of asphalt emulsion recycled mixture with reclaimed cement-stabilized macadam. Constr. Build. Mater. 2016, 118, 146-154. [CrossRef]

4. Li, W.; Lang, L.; Lin, Z.; Wang, Z.; Zhang, F. Characteristics of dry shrinkage and temperature shrinkage of cement-stabilized steel slag. Constr. Build. Mater. 2017, 134, 540-548. [CrossRef]

5. Behera, M.; Bhattacharyya, S.K.; Minocha, A.K.; Deoliya, R.; Maiti, S. Recycled aggregate from C\&D waste \& its use in concrete-A breakthrough towards sustainability in construction sector: A review. Constr. Build. Mater. 2014, 68, 501-516.

6. Fatemi, S.; Imaninasab, R. Performance evaluation of recycled asphalt mixtures by construction and demolition waste materials. Constr. Build. Mater. 2016, 120, 450-456. [CrossRef]

7. Lu, W.S.; Webster, C.; Peng, Y.; Chen, X.; Zhang, X.L. Estimating and calibrating the amount of building-related construction and demolition waste in urban China. Int. J. Const. Manag. 2017, 17, 13-24. [CrossRef]

8. Zhou, J.; Zeng, M.; Chen, Y.; Zhong, M. Evaluation of cement stabilized recycled concrete aggregates treated with waste oil and asphalt emulsion. Constr. Build. Mater. 2019, 199, 143-153. [CrossRef]

9. Shi, C.; Li, Y.; Zhang, J.; Li, W.; Chong, L.; Xie, Z. Performance enhancement of recycled concrete aggregateA review. J. Clean Prod. 2016, 112, 466-472. [CrossRef]

10. Kirthika, S.K.; Singh, S.K.; Chourasia, A. Alternative fine aggregates in production of sustainable concreteA review. J. Clean Prod. 2020, 268. [CrossRef]

11. Shaker, R.M.; Bhalala, M.; Kargar, Q.; Chang, B. Evaluation of Alternative Home-Produced Concrete Strength with Economic Analysis. Sustainability 2020, 12, 6746. [CrossRef]

12. Mills-Beale, J.; You, Z.P. The Mechanical Properties of Asphalt Mixtures with Recycled Concrete Aggregates. Constr. Build. Mater. 2010, 24, 230-235. [CrossRef]

13. Paranavithana, S.; Mohajerani, A. Effects of recycled concrete aggregates on properties of asphalt concrete. Resour. Conserv. Recycl. 2006, 48, 1-12. [CrossRef]

14. De Juan, M.S.; Gutiérrez, P.A. Study on the influence of attached mortar content on the properties of recycled concrete aggregate. Constr. Build. Mater. 2009, 23, 872-877. [CrossRef] 
15. Meyer, C. The greening of the concrete industry. Cem. Concr. Compos. 2009, 31, 601-605. [CrossRef]

16. Bravo, M.; De Brito, J.; Pontes, J.; Evangelista, L. Mechanical performance of concrete made with aggregates from construction and demolition waste recycling plants. J. Clean. Prod. 2015, 99, 59-74. [CrossRef]

17. Kampala, A.; Horpibulsuk, S.; Chinkullijniwat, A.; Shen, S.L. Engineering properties of recycled calcium carbide residue stabilized clay as fill and pavement materials. Constr. Build. Mater. 2013, 46, $203-210$. [CrossRef]

18. Lopez-Uceda, A.; Agrela, F.; Cabrera, M.; Ayuso, J.; López, M. Mechanical performance of roller compacted concrete with recycled concrete aggregates. Road Mater. Pavement Des. 2018, 19, 36-55. [CrossRef]

19. Kou, S.C.; Poon, C.S.; Wan, H.W. Properties of concrete prepared with low-grade recycled aggregates. Constr. Build. Mater. 2012, 36, 881-889. [CrossRef]

20. Kumar, R. Influence of recycled coarse aggregate derived from construction and demolition waste (CDW) on abrasion resistance of pavement concrete. Constr. Build. Mater. 2017, 142, 248-255. [CrossRef]

21. Paul, S.C.; Panda, B.; Garg, A.G. A novel approach in modelling of concrete made with recycled aggregates. Measurement 2018, 115, 64-72. [CrossRef]

22. Akbarnezhad, A.; Ong, K.C.G.; Tam, C.T.; Zhang, M.H. Effects of the parent concrete properties and crushing procedure on the properties of coarse recycled concrete aggregates. J. Mater. Civ. Eng. 2013, 25, 1795-1802. [CrossRef]

23. Ma, K.; Li, W.B. Effect of the Aggregate Size on Strength Properties of Recycled Aggregate Concrete. Adv. Mater. Sci. Eng. 2018, 2018, 2428576. [CrossRef]

24. Ozbakkaloglu, T.; Gholampour, A.; Xie, T. Mechanical and durability properties of recycled aggregate concrete: Effect of recycled aggregate properties and content. J. Mater. Civ. Eng. 2018, 30. [CrossRef]

25. Ji, X.P.; Jiang, Y.J.; Liu, Y.J. Evaluation of the mechanical behaviors of cement-stabilized cold recycled mixtures produced by vertical vibration compaction method. Mater. Struct. 2016, 49, 2257-2270. [CrossRef]

26. Taha, R.; Al-Harthy, A.; Al-Shamsi, K.; Al-Zubeidi, M. Cement stabilization of reclaimed asphalt pavement aggregate for road bases and subbases. J. Mater. Civ. Eng. 2002, 14, 239-245. [CrossRef]

27. Disfani, M.M.; Arulrajah, A.; Haghighi, H.; Mohammadinia, A.; Horpibulsuk, S. Flexural beam fatigue strength evaluation of crushed brick as a supplementary material in cement stabilized recycled concrete aggregates. Constr. Build. Mater. 2014, 68, 667-676. [CrossRef]

28. Hou, Y.Q.; Ji, X.P.; Liu, L.Q. Study on Mechanical and Influencing Factors of Cement Stabilised Recycled Aggregate. J. Highw. Transp. Res. Dev. 2016, 33, 56-61.

29. Mohammadinia, A.; Arulrajah, A.; Sanjayan, J.; Disfani, M.M.; Bo, M.W.; Darmawan, S. Laboratory Evaluation of the Use of Cement-Treated Construction and Demolition Materials in Pavement Base and Subbase Applications. J. Mater. Civ. Eng. 2015, 27. [CrossRef]

30. Ministry of Transport of the People's Republic of China. China Professional Standard: JTG E42, Test. Methods of Aggregate for Highway Engineering; China Communication Press: Beijing, China, 2005.

31. Ministry of Transport of the People's Republic of China. China Professional Standard: JTG E51, Test. Methods of Materials Stabilized with Inorganic Binders for Highway Engineering; China Communication Press: Beijing, China, 2009.

32. Rahal, K. Mechanical properties of concrete with recycled coarse aggregate. Build. Environ. 2007, 42, 407-415. [CrossRef]

33. Ji, X.P.; Cao, H.L.; Liu, L.Q. Performance and influencing factors of cement stabilized recycled concrete aggregate. J. Build. Mater. 2016, 19, 342-346. (In Chinese)

34. Farhan, A.H.; Dawson, A.R.; Thom, N.H. Effect of cementation level on performance of rubberized cement-stabilized aggregate mixtures. Mater. Des. 2016, 97, 98-107. [CrossRef]

35. Ministry of Transport of the People's Republic of China. China Professional Standard: JTG D50, Specifications for Design of Highway Asphalt Pavement; China Communication Press: Beijing, China, 2017.

36. Liu, D.; Li, L.H.; Cui, H.J. Strength performance of cement stabilized aggregate containing bottom ash aggregate (BAA). J. Build. Mater. 2014, 17, 538-542. (In Chinese)

37. Du, Q.; Pan, T.; Lv, J.; Zhou, J.; Ma, Q.W.; Sun, Q. Mechanical Properties of Sandstone Cement-Stabilized Macadam. Appl. Sci. 2020, 9, 3460. [CrossRef]

38. Zhang, H.W. Experimental Study on Road Performance of Recycled Aggregate for Waste Concrete Pavement. Master's Thesis, Zhengzhou University, Zhengzhou, China, 2019. 
39. Gao, J.Q.; Jin, P.P.; Sheng, Y.X.; An, P. A case study on crack propagation law of cement stabilised macadam base. Int. J. Pavement Eng. 2020, 21, 516-523. [CrossRef]

40. Katz, A. Properties of concrete made with recycled aggregate from partially hydrated old concrete. Cem. Concr. Res. 2003, 33, 703-711. [CrossRef]

(C) 2020 by the authors. Licensee MDPI, Basel, Switzerland. This article is an open access article distributed under the terms and conditions of the Creative Commons Attribution (CC BY) license (http://creativecommons.org/licenses/by/4.0/). 